\title{
Thermal behavior of lignocellulosic materials under aerobic/anaerobic environments
}

\begin{abstract}
Utilization of lignocellulosic material via thermo-chemical processes has received huge attention from both biofuel and biochemical sectors. Intensive research has been embarked to study the thermal behavior and the decomposition patterns of the potential feedstock materials. Palm plantation waste, empty palm fruit's bunches (EFB) are used as a biomass source in this experiment. A comparison study was made using basic lignocellulosic model compounds such as hemicellulose, cellulose, and lignin. The thermal stability of each compound in both oxygen and nitrogen environments was investigated. The degradation of model compounds were categorized into primary $\left(200-400{ }^{\circ} \mathrm{C}\right)$ and secondary $\left(500-800{ }^{\circ} \mathrm{C}\right)$ stages based on structural collapse and liquid/solid decompositions. Besides, the influence of inorganic substances in EFB degradation was reported whereby the mineral contents act as a catalyst by enhancing the decomposition at lower temperatures compared to demineralized EFB. In addition, the product gas evolutions from the gasification reaction of the components were analyzed using online mass spectrometer. The gas production patterns indicate the nature of the compounds in terms of thermal stability, functional group cleavages and catalytic reactions.
\end{abstract}

Keyword: EFB; Hemicellulose; Cellulose; Lignin; Hydrogen; TGA 